Brit. F. vener. Dis. (1971) 47, 146

\title{
Attitudes of hospitals in London to venereal disease in the 18th and 19th centuries
}

\author{
M. A. WAUGH \\ West London Hospital, Charing Cross Hospital Group
}

From early times sexually transmitted disease was seen as a problem in the growing metropolis. In 1161 the brothel keepers of Southwark were forbidden to house 'women suffering from the perilous infirmity of burning'. In 1430 brothel keepers were obliged to prevent the admission of men suffering from infirmitus nefanda-the hidden disease (Morton, 1966).

By 1561 venereal diseases were treated at St. Thomas's Hospital in the four sweat wards, Job, Lazarus, Judith, and Susanna; these were situated at the back of the hospital, an omen perhaps of modern prejudice against V.D. clinics. These sweat wards were a forerunner of later methods of treatment. The patient was rubbed with mercurial ointments in front of a warm fire and then wrapped up in flannel (Fig. 1). Hot baths were also used and the patient was segregated from other inmates and forbidden to leave until he was cured (McInnes, 1963).

By the mid-18th century there was again an up-surge of interest in the venereal diseases.

In 1736 a committee was asked by the Governors of Westminster Hospital to confer with St. Bartholomew's, St. Thomas', and 'the hospital at Hyde Park Corner', i.e. St. George's, 'as to the best method to prevent the entertaining of any patients who have contracted the distemper by drinking gin and other spiritous liquors and to desire them to co-operate with this society in discontinuing that most per-

FIG. 1 'The Pox'. Treatment of the venereal disease by inunctions and inhalations, from Blankaart (1684), facing p. 39. By courtesy of the Wellcome Trustees

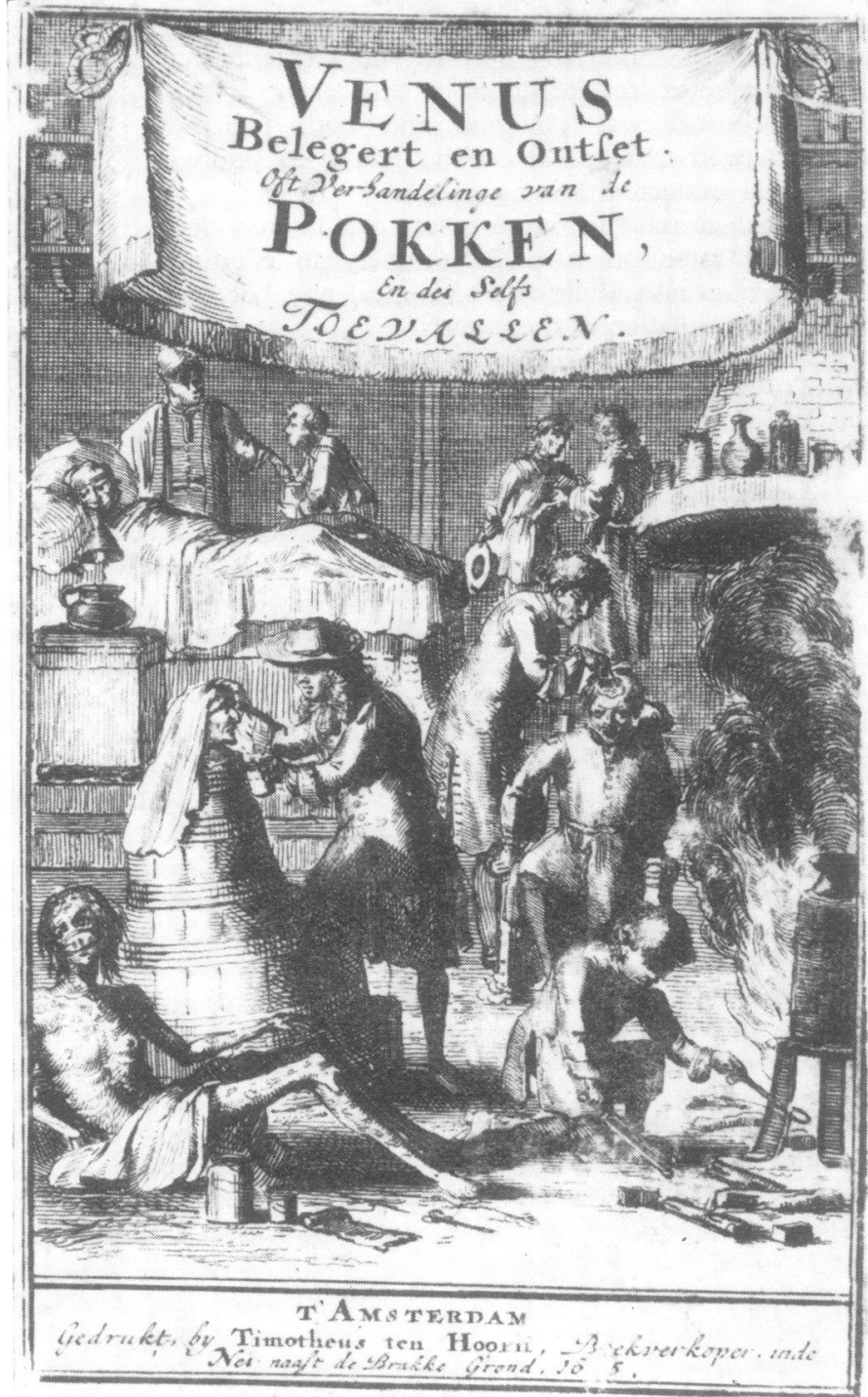


nicious practice'. In 1738 the Westminster Hospital refused to admit cases of venereal disease, unless the patient gave 'an extra-ordinary contribution to his support'. Any patient found to have a venereal disease was to be immediately discharged without awaiting cure. At the same time a letter of disgust was read from lady subscribers to the hospital protesting against the admission of venereal patients (LangdonDavies, 1952).

On the other side of London, the London Hospital reacted differently (Clark-Kennedy, 1962, 1963). In 1741 it was resolved 'that all such patients whose cases required a salivation, whether venereal or otherwise, are proper subjects of this charity'. Within a month a house was taken in Prescott Street at a rent of $£ 15$ per annum. A matron was appointed and to 'the Lock' were sent cases not only of syphilis but smallpox and other contagious fevers. However, troubles arose; Grimes, the porter and messenger, and Toulson, the general labourer, shared a bed there and nurses were often lodged in the Lock when there was no room for them in the main hospital. After that time there was a hardening in the attitude to admitting cases of venereal disease, but patients kept on trickling in and further developments took place in the mid-19th century.

The Middlesex Hospital, founded in 1745, soon restricted the numbers of patients with venereal diseases by demanding 2 guineas weekly-a not inconsiderable sum in those times (Saunders, 1949).

The desire to segregate cases of venereal disease led to the founding of a special hospital for venereal cases (Highmore, 1814). The Lock Hospital at Hyde Park Corner (Fig. 2) was constituted on July 4, 1746, for the relief of venereal patients only. The name Lock is derived from Loke-a house for lepers. The Lock Hospital was founded on motives of reform. Reasons given were that if a syphilitic was left destitute, 'he would diffuse the misery and spread it', and 'Many innocent women of irreproachable characters themselves have received infection from the profligacy of their husbands'. This foundation in 1746 compares favourably with the attitude in Paris, where in the 1780s there was a special hospital in the Rue St. Jacques, later in $\mathbf{1 8 3 6}$ at Rue Loraine, under

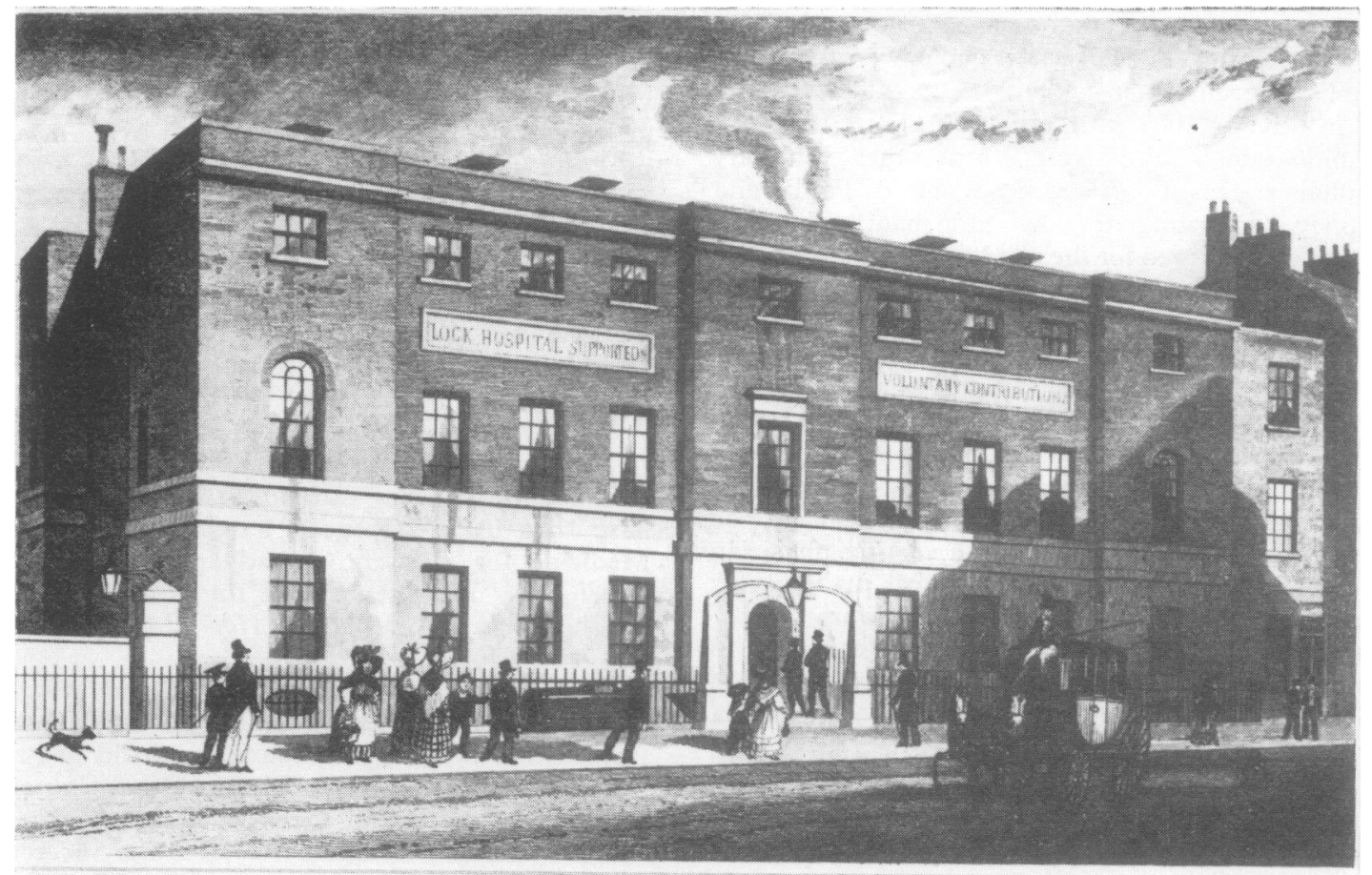

FIG. 2 The Lock Hospital, Hyde Park Corner. From an engraving, 19th cent. By courtesy of the Wellcome 
Ricord, who had to 'wait' 20 years to be admitted to the Academy of Medicine.

Highmore (1814) stated that venereal patients were still excluded from most other public charities and were still inadmissible to many of the hospitals. Even at the Lock Hospital at Hyde Park Corner, the patients, who were admitted weekly on Thursdays in the forenoon, had to deposit $£ 111 \mathrm{~s} .6 \mathrm{~d}$. on admission; but for that they were supplied with food, clean linen, free treatment, and burial if need be. There was always a waiting list.

Reformation played a large part in the Lock Hospital. There were two services on Sundays and the chaplains made rounds during the week. In 1787, an asylum, later called a rescue home, was set up there for fallen women; this had a quite remarkable success and it was moved to the Harrow Road in 1841 (Pevsner, 1952), to a building on land bought from the executors of Mrs. Siddons, the actress, next door to Paddington Workhouse, now part of Paddington General Hospital-St. Mary's Hospital.

The Lock Hospital at Hyde Park Corner was run by a committee selected from the governors. Five guineas per annum made one a governor and $£ 50$ a governor for life. The governors had powers to recommend a person for in-patient treatment, a practice still in force in 1902 (Burdett, 1902). Later the Lock Hospital would admit cases from other voluntary hospitals and the Poor Law hospitals. 'At Poplar and Stepney (according to Dr. Stoneham), the sick asylum was reserved for the resident poor ... Venereal cases were never admitted to the infirmary but a few were sent to the Lock Hospital at a weekly cost of 17 shillings' (Royal Commission on the Poor Laws, 1905-1909). The medical staff, who gave their services gratis, consisted in $\mathbf{1 8 1 4}$ of four honoraries. In addition there was a house pupil, later called house surgeon, matron, nurses, and servants, and ambulant patients sometimes helped. The house pupil had to be always in attendance. He saw the visiting physician from 11 a.m. to 3 p.m., and afterwards made up his prescriptions. He acted as dresser, made up the admission and discharge lists, and was expected to report any misbehaviour by the patients.

In 1788, the Lock Hospital had three male and three female wards, the walls of which were said to need white-washing (Howard, 1789). There was also a chapel. On September 22, 1788, there were 36 men and 28 women patients. From 1746 to 1808 30,222 patients were judged cured. In the year March 25, 1808, to March 25, 1809, 355 in-patients were cured and twenty out-patients also. Forty patients 'eloped without being discharged', eleven were discharged for ill behaviour, and six died. On March 25, 1809, there were 67 in-patients. These statistics are given by Highmore (1814). See Fig. 3.

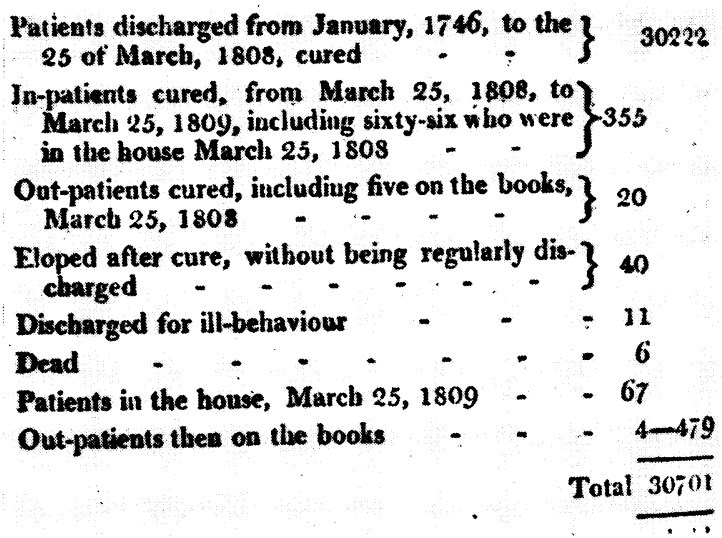

FIG. 3 The Lock Hospital. Details of patients, fanuary, 1746 to March 25, 1809, from Highmore (1814), p. 150. By courtesy of the Wellcome Trustees

It was the policy of the Lock Hospital never to readmit a patient who had been discharged; this was supposed to reform the patient.

By 1841 the hospital had grown, 135 female beds were moved to Harrow Road and 27 male beds together with out-patients were moved to the hospital in Dean Street, now the West End Hospital for Nervous Diseases. In 1902 there was a medical staff of fourteen (Burdett, 1902), the Consultant Physician being Sir E. H. Sieveking (Goodman, 1968), who had been called in to advise the Prince of Wales and Princess Alexandra as early as 1863 (unfortunately records regarding this consultation have been destroyed).

Sir Edward Sieveking (Fig. 4) was born in London in 1816, and after studies at University College, qualified M.D. from Edinburgh in 1841. He must have then been influenced by the Paris School of Medicine for he went abroad and studied at the Hotel Dieu, under Andral, at the Hôpital St. Louis for skin diseases, and at the Hopital du Midi under the great Ricord.

He settled in Manchester Square, and proceeded M.R.C.P. in 1847. In 1851 he was appointed Assistant Physician to St. Mary's Hospital, and did not retire from the staff until 1888. He made two important translations, both for the Sydenham Society, of which Jonathan Hutchinson was the Secretary: in 1849 Vol. 2 of the four volume 'Manual of Pathological Anatomy' by Rokitansky, and in 1853 the first comprehensive work on neurology, 'A Manual of the Nervous Diseases of Man' by Romberg.

$\mathrm{He}$ became in succession physician to the Duke 


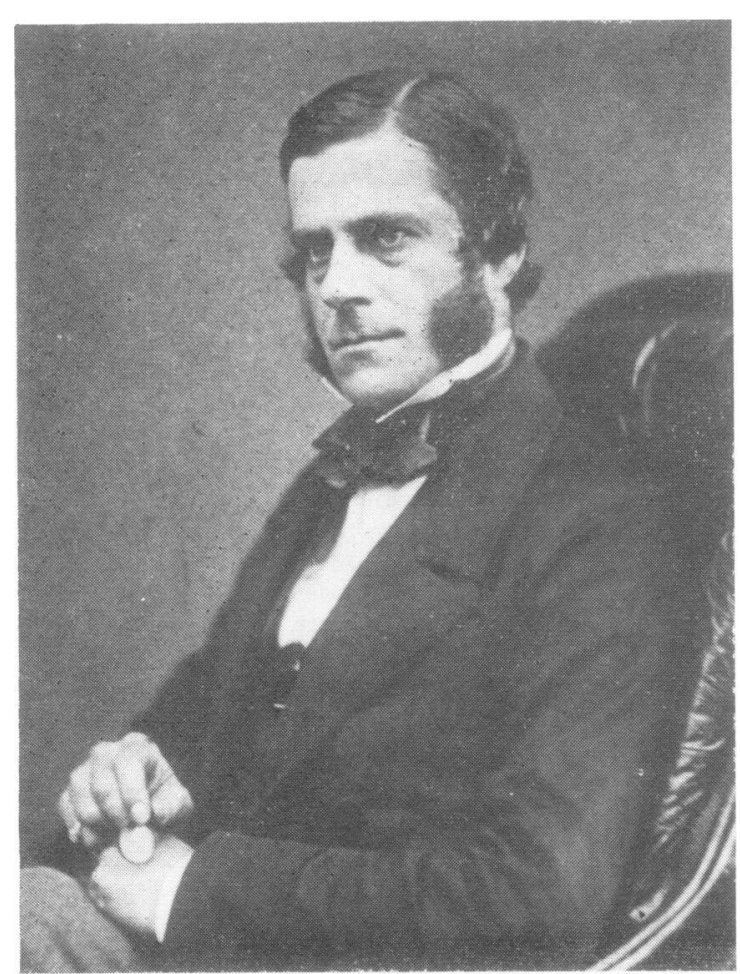

FIG. 4 Sir Edward Henry Sieveking (1816-1904), from an original photograph by Maull and Polyblank. By courtesy of the Wellcome Trustees

of Cambridge, the Prince of Wales, and Queen Victoria, and was appointed physician to the Lock Hospital in 1866, keeping the post till his death in 1904.

An amusing note in the 1890 s states that 'Patients were in the habit of quitting the hospital in a diseased state on such occasions as the Derby week fairs for the purpose of pursuing their avocation' (Select Committee on Metropolitan Hospitals, 1890-93). Try as they might the house committees could not keep out venereal cases. As a result of the disbandment of soldiers the venereal disease rate increased at home after Waterloo (Parsons, 1932-36). In February, 1817, twenty additional beds in a temporary ward called 'Regency' were set up for the treatment of venereal cases at St. Thomas'. Hutchinson (1887) quoted a religious tract entitled 'The Conversion and Subsequent History of Benjamin Lawson, an afflicted youth deprived of his speech by scrofula on account of which he was for nine weeks an indoor patient in King's Ward, St. Thomas' Hospital, in the year 1815'. This was the story of a youth of 19, under the care of Mr. Cline, who was treated for congenital syphilis and lived another 10 years. The boy's father was also admitted to the Middlesex Hospital at about the same time with tertiary syphilis.

In 1818 Benjamin Brodie, the assistant surgeon to St. Georges Hospital, gave the first recorded picture of what is now called Reiter's disease in his text-book 'Pathological and Surgical Observations on Diseases of the Joints' (Brodie, 1818). This was a case in a man of 45 with urethral discharge, fever, joint swellings, and inflammation of the eyes.

Brodie was a contemporary of Sir Astley Cooper, 1768-1841, who was Surgeon to Guy's from 1800 to 1825 , and in the Spring of 1824 gave a remarkable series of lectures at St. Thomas's Hospital on Venereal Diseases. These were published in the Lancet of the period. He gave his often brilliant and forward views in these lectures punctuated with some earthy comments and aphorisms (Cooper, 1824).

One of his comments which brought a change in treatment and administration was: 'a man who gives mercury in gonorrhoea deserves to be flogged out of his profession because he must be quite ignorant of the principle in which the disease is cured'.

In May the Lancet published a report entitled 'Sit Astley Cooper and the Surgeons of the Borough Hospitals. Opening of the Syphilitic Wards at Guy's under New and Improved Regulations' (Lancet, 1824). The editor wrote 'We cannot forbear calling the attention of the profession and the public to the gratifying fact that the publication in the Lancet of Sir Astley Cooper's many and indignant observations on the infamous treatment of patients for Gonorrhoea which had long prevailed in the Borough Hospitals has been almost immediately followed by an official announcement that the practice of ruining the health and frequently destroying the lives of patients by unnecessary salivations will be no longer part of the system and that the venereal wards of Guy's Hospital will shortly be opened under new and improved regulations'.

In 1862, on the departure of St. Thomas' Hospital from Southwark to Surrey Gardens, there was a shortage of space and venereal cases were no longer taken as in-patients (McInnes, 1963).

The Westminster Hospital meanwhile was constantly changing its attitude to the admission of venereal patients (Langdon-Davies, 1952). This could be explained by the fact that most board meetings were badly attended and that the decisions made were unrepresentative.

Sir Anthony Carlisle, born 1768 and from 1793 to 1840 surgeon to the Westminster Hospital, stated in 1831 that the prostitutes he had seen were invariably infertile but that after being sent on the long trip to 
Botany Bay and being deprived of intercourse for 6 to 8 months, they often became remarkably prolific on land fall (Parliamentary Papers, 1831-32). In 1834, Queen Anne Ward was specified as a place for female syphilitics. In 1841 there were nineteen cases of primary syphilis, 22 of secondary syphilis, and 32 of gonorrhoea in the hospital when the Board met; in 1842 the Board forbade the further admission of syphilitics. This order could not have remained in force, for in 1848 a nurse was dismissed for overenthusiastic use of mercurial ointment causing damage to the life of a patient, and in 1856 six urgent cases of syphilis in females had to be dealt with by admission to a separate ward. In the same year a house surgeon was reprimanded for admitting a case of gonorrhoea, which should have been admitted only on the R.M.O.'s authority.

The Poor Law hospitals were far worse. The Lancet Commission stated 'the female itch ward at Chelsea was the nastiest place altogether that our eyes have looked upon'. A ward for syphilitic women was found where the eight inmates had one round towel a week (Abel-Smith, 1964).

The situation was much brighter at the London (Clarke-Kennedy, 1962, 1963). In 1858 the Council decided that they could not prevent the admission of venereal patients much longer and they were getting in unofficially anyway. So Hannah Ward was opened with beds for seven acute cases. Much of the practice of Sir Jonathan Hutchinson (1828-1913) was based on syphilis. He had no hesitation in using his power and influence to treat interesting cases of syphilis at his hospital, patients being referred by local practitioners and physicians from provincial hospitals. $\mathrm{He}$ also had a flourishing practice in syphilis at the Royal London Ophthalmic Hospital (later Moorfield's), the Metropolitan Free hospitals, and the Blackfriars Hospital for Diseases of the Skin (Hutchinson, 1887).

Just after the end of the century, in 1915, the Grocers' Company subscribed towards the building of the two new storeys on the Fielden Isolation Block, called St. Anthony's ward. 2,000 patients were treated annually. After the present venereal diseases department was opened and with the discovery of insulin in 1923, St. Anthony's ward was reallocated to the management of diabetes and renamed Grocer's ward.

\section{Summary}

The author presents a brief historical account of the attitudes of hospitals in London in the 18th and 19th centuries towards the provision of facilities for the treatment of patients with venereal disease.

\section{References}

ABeL-SMrth, B. (1964) 'The Lancet Sanitary Commission for Investigating the State of the Infirmaries of Workhouses', in 'The Hospitals, 1800-1948', p. 50-65. Heinemann, London

BLANKAART, S. (1684) 'Venus belegert en Ontset'. Hoorn, Amsterdam.

BRODIE, B. C. (1818) 'Pathological and Surgical Observations on Diseases of the Joints'. Longmans, London - (1824) Lancet, 3, 197. Report of a lecture given on April 18, 1924

BuRdeTt, Sir HENRY (1902) 'Burdett Hospitals and Charities'. London

Clark-Kennedy, A. E. (1962-63) 'The London', vol. I 1962, vol. II 1963. Pitman, London

COOPER, Astley (1824) May 18 Lancet, p. 197. Report of lecture given on April 18, 1824

Goodman, N. M. (1968) In 'Medicine and Science in the 1860 's', ed. F. N. L. Poynter. Wellcome Institute, London

HighmoRe, A. (1814) 'Pietas Londinensis. The History, Design and Present State of the Public Charities in and near London'. Cradock and Joy, London

HowARD, J. (1789) 'An Account of the Principal Lazarettos in Europe'. Warrington

Hutchinson, J. (1887) 'Syphilis'. Cassell, London

Lancet (1824) May 22, 3, 240.

- (1866) 'Sanitary Commission Reports'

LANGDON-DaviEs, J. (1952) 'The Westminster Hospital, 1719-1948'. Murray, London

MCINNES, E. M. (1963) 'St. Thomas' Hospital'. Allen and Unwin, London

MORTON, R. S. (1966) 'Venereal Diseases'. Penguin Books, London

Parsons, F. G. (1932-36) 'History of St. Thomas's Hospitals', vol. 3, pp. 43-44. Methuen, London

'Parliamentary Papers, 1831 to 1832 ', vol. 15 , p. 563

Pevsner, N. (1952) 'The Buildings of England: London except the Cities of London and Westminster'. Penguin Books, London

'Royal Commission on the Poor Laws, 1905-1909'; vol. II, Dr. Stoneham's Evidence. Cd. 4684 Qo. 21508 and 21550.

SAUNDERS, H. St. G. (1949) 'The Middlesex Hospital, 1745-1948'. Parrish, London

'Select Committee on Metropolitan Hospitals, 18901893'. Third Report, pp. ci-ciii

\section{Conceptions hospitalières vis-à-vis des maladies vénériennes à Londres au $18^{\mathrm{e}}$ et ${ }^{19}{ }^{\mathrm{e}}$ siècles}

SOMMAIRE

L'auteur fait un bref exposé historique sur les conceptions hospitalières à Londres au cours du $18^{\mathrm{e}}$ et $19^{\mathrm{e}}$ siècles concernant les dispositions offertes aux vénériens pour leur traitement. 